\title{
Hemispheric differences in the perception of gratings
}

\author{
E. SZELAG, W. BUDOHOSKA, and B. KOLTUSKA \\ Nencki Institute of Experimental Biology, Warsaw, Poland
}

\section{(Charles W. Eriksen, Sponsor)}

An experiment was designed to test the role of the hemispheres in the processing of gratings. Subjects judged whether two spatial frequencies presented in succession in either the right or the left visual field were the same or different. Hemispheric differentiation was measured by comparing mean reaction times and percentages of erroneous responses. The results showed an absence of hemispheric differences, which suggests that gratings are processed in both hemispheres with equal efficiency. The findings are interpreted as indicating that the matching procedure involves simple sensory features of patterns and suggest that the functional asymmetry of hemispheres does not extend to the earliest stages of information processing.

Visual pattern perception is conceived by some authors as involving an analysis of patterns into their component gratings (Braddick, Campbell, \& Atkinson, 1978; Kaufman, 1979). Electrophysiological studies of perception in cats have revealed that certain cells in the cat's visual projective cortex react selectively to gratings of specific spatial frequency (de Valois, Albrecht, \& Thorell, 1982; Maffei \& Fiorentini, 1973, 1977; Movshon, Thompson, \& Tolhurst, 1978). Taking it for granted that a sensory input is processed at successive levels in the nervous system and that any classificatory decision assigning the perceived pattern to a particular category is preceded by information processing in the sensory cortex, we would assume that the decomposition of a pattern into gratings is accomplished at an early stage of visual information processing. Thus, no hemispheric differences should be observed in grating perception. This hypothesis would have to be tested in view of the divergent theories regarding the role of the hemispheres in sensory information processing and regarding the stage of processing at which hemispheric differentiation comes into effect. According to some authors, functional differentiation takes place at an early processing stage (Hellige \& Webster, 1979; Pennal, 1977; Pirot, Pulton, \& Sutker, 1977). Others believe that it occurs only in the processing of the more complex features, for example, visuospatial or semantic features (Moscovitch, 1979; Moscovitch, Scullion, \& Christie, 1976; Rotkin, Greenwood, \& Gazzaniga, 1977; Scotti \& Spinnler, 1970; Sergent, 1983). These divergent findings, as well as the electrophysiological data suggesting that grating is processed at the lower levels of the nervous system, have induced us to investigate hemispheric differences in grating perception.

The authors' mailing address is: Department of Neurophysiology, Nencki Institute of Experimental Biology, 02-093 Warsaw, 3 Pasteur Str., Poland.

\section{METHOD}

\section{Subjects}

We tested 12 right-handed subjects with normal or corrected-to-normal vision who were not aware of any case of left-handedness among their close relatives. Handedness was tested with a short questionnaire (Briggs \& Nebes, 1975)

\section{Material}

The experiment was based on comparison of two successively presented stimuli. The set of stimuli consisted of 15 different horizontal gratings presented square wave. The spatial frequency differed from one stimulus to another by a difference derived from a logarithmic curve (see Figure 1). Hence, the gratings were such that each band was clearly discernible, according to the relevant literature (Campbell \& Maffei, 1976). A stimulus measured $2^{\circ}$ in width and $3^{\circ}$ in height; exposure time was $\mathbf{4 0} \mathrm{msec}$. The patterns were projected on a screen from slides from a Kodak-Carousel projector with electronic shutter. They were presented laterally either $2^{\circ}$ right or $2^{\circ}$ left of the fixation point, (i.e., a black dot $38^{\prime}$ in diameter) that was mounted permanently in the center of the screen. The luminance of the pattern was $16.5 \mathrm{~lx}$, and luminance of the screen was $7 \mathrm{~lx}$.

\section{Procedure}

Subjects were tested in a soundproof chamber. A subject was seated $1.5 \mathrm{~m}$ from the screen, on which two gratings were presented in succession. The subject's task was to compare the two stimuli and decide whether the second grating differed from the first one or whether it was the same. The two stimuli were separated by an interval of $1.5 \mathrm{sec}$. They were both exposed in the right visual field (RVF) or in the left visual field (LVF). Each stimulus pair was preceded by a warning signal (gong) sounded $800 \mathrm{msec}$ before the onset of the first stimulus. The subject responded by pressing with his/her thumb one of two buttons, $1 \mathrm{~cm}$ apart in vertical arrangement (i.e., one closer to and the other farther from the subject). One button was pressed for a "same" response, the other for "different." Throughout the testing the subject had his/her finger poised between the two buttons. Pressing a button stopped an electronic counter that was started at the onset of the second stimulus. The interval between two successive stimulus pairs was $2 \mathrm{sec}$. Subjects were urged to respond as quickly as possible, and they were permitted to correct erroneous response. Those trials in which the subject had responded incorrectly or had corrected the response were run again at the end of the given series in the original order. The idea was to obtain a large enough number of reaction times of the correct response type. The scale of difficulty across trials was made uniform by contrasting in each differ- 


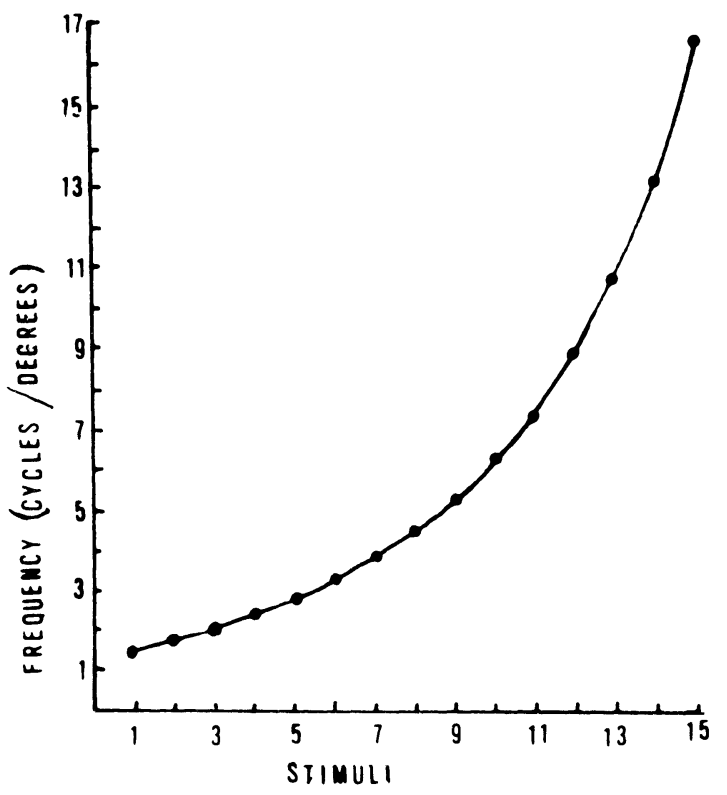

Figure 1. Stimuli used in this experiment.

ent pair stimuli differing by four points on the curve depicted in Figure 1. A same pair comprised two presentations of the same grating. The actual experiment was preceded by a preliminary series during which the subject became familiar with the task, learned to concentrate upon the fixation point, and practiced pressing the correct button.

The experiment itself consisted of two experimental sessions, each lasting $90 \mathrm{~min}$, held at an interval of several days. Each session comprised 186 trials. The entire experimental design was fully balanced for visual field (half the gratings in the LVF, the other half in the RVF), hand used for pressing (left vs. right), and type of button (same vs. different).

The subject's eye movements were followed closely on a TV monitor. Those trials during which the subject was found to move his/her eyes were repeated at the end of the series.

\section{RESULTS}

The validity of the comparisons was assessed on two criteria: reaction time and response correctness. To eliminate disproportionately long or short reaction times that may have been due to chance, we employed the Dixon test for data selection (Kirk, 1968). The statistical analysis was based on mean reaction times (RT) and on percent of errors. Three-way analysis of variance comprised the following experimental variables: visual field (LVF vs. RVF), kind of comparison ("same" vs. "different"), and hand (right vs. left).

Analysis of variance for reaction times yielded only one main effect: kind of comparison $[F(1,11)=8.87$, $p<.025]$. Mean RT to same gratings $(831.2 \mathrm{msec})$ was $40.3 \mathrm{msec}$ shorter than mean RT to different gratings $(871.5 \mathrm{msec})$. This difference was observed for 10 out of our 12 subjects. The other factors tested by the analysis of variance (i.e., visual field and hand), as well as all other interactions, failed to reach statistical significanoe (see Figure 2). In view of Sergent's (1983) findings, we compared the responses to patterns of high and low gratings. Of the 15 patterns used in the experiment, the three highest gratings (with frequencies from 16.8 to 10.6 cycles per degree) were assigned to the category of high-frequency gratings, and the three lowest (1.4 to 2.0 cycles per degree) to the category of low-frequency gratings (see Figure 1). The data obtained in each category for same stimuli were subjected to a twoway analysis of variance testing visual field (left vs. right) and frequency (low vs. high). We found neither a significant effect for any of the two factors nor an interaction between them $[F(1,11)=1.63$, n.s.]. The mean RT for lowfrequency gratings ( $822.0 \mathrm{msec}$ ) was $32.1 \mathrm{msec}$ shorter than RT to high-frequency gratings (789.9 msec). This difference was observed in 8 out of our 12 subjects, and this tendency failed to reach statistical significance $[F(1,11)=4.03$, n.s.].

A three-way analysis of variance for percentage of errors failed to reveal the statistical significance of any of the tested factors (see Figure 3). The only significant interaction was found between visual field and kind of matching $[F(1,11)=6.46, p<.05]$. The interaction was due to the significantly higher number of errors $(p<.05$, Duncan test) for the RVF in matching different gratings than for the two fields in matching same gratings (by $1.82 \%$ for LVF and by $6.89 \%$ for RVF). In matching different stimuli in the LVF, subjects made about the same number of errors as in matching same stimuli in the two visual fields (see Figure 3). This interaction might have been due to the opposite direction of hemispheric differences for same and different matches. In the same matches, a smaller number of errors was recorded for the RVF; in different matches, a smaller number was recorded for the LVF. These two tendencies failed to reach statistical significance, however (Duncan test, Figure 3).

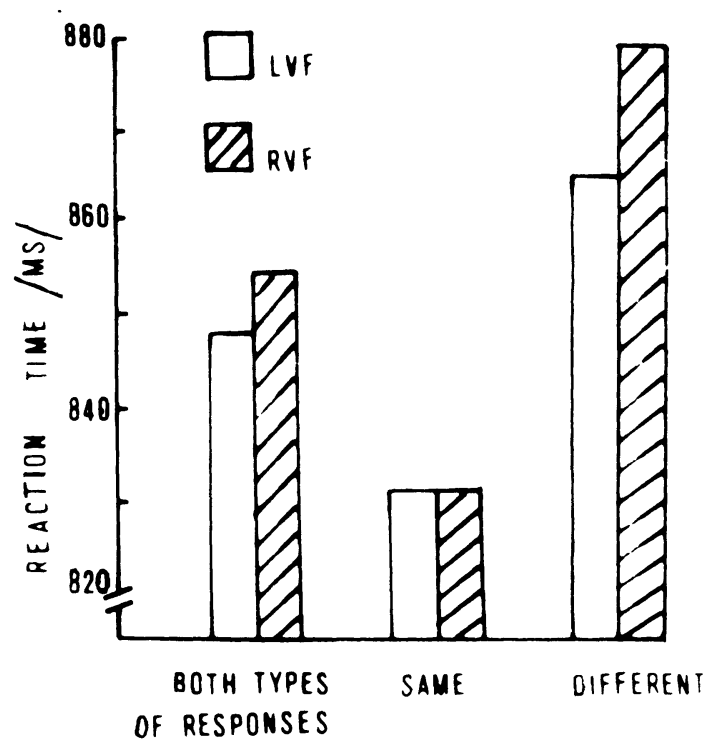

Figure 2. Mean reaction times (in milliseconds) in the left and right visual field for both types of responses and separately for "same" and "different" responses. 


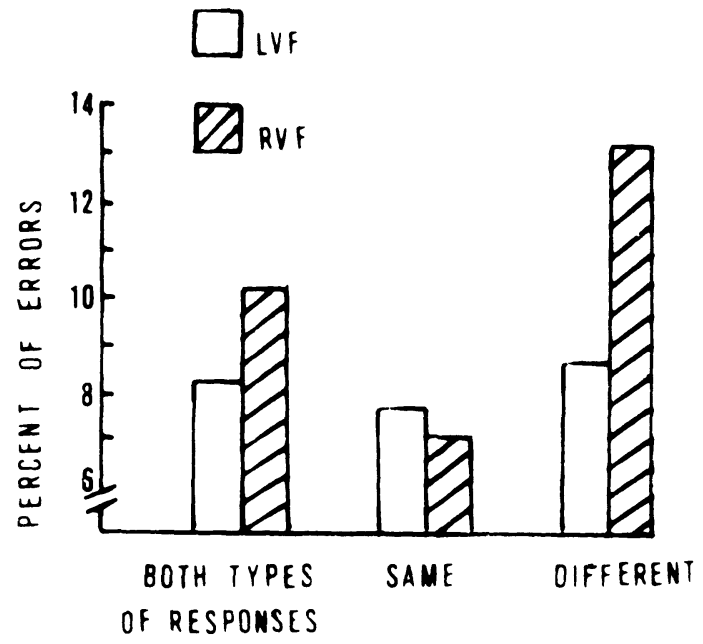

Figure 3. Percent of errors in the left and right visual field for both types of responses and separately for "same" and "different" responses.

\section{DISCUSSION}

The absence of hemispheric differentiation in the perception of grating, based on measures of reaction time and on percentage of errors, suggests that grating is processed in the right and left hemispheres with equal efficiency. This finding holds for both high and low frequencies, and concurs with the results reported by Beaton and Blakemore (1981), Fiorentini and Berardi (1984), and Vassilev, Verskaya, Manahilov, Mitov, and Leushina (1985). The results also agree with Sergent's (1983) hypothesis to the effect that hemispheric differences do not come into evidence at the sensory level. Our results do not confirm Sergent's (1982, 1983) views concerning the differentiation of hemispheric functions in relation to grating type. According to Sergent's view, higher spatial frequencies are more efficiently handled by the left hemisphere and low spatial frequencies are handled by the right hemisphere. No such relationship has been revealed in our analysis, which tallies with the findings repor ted by Fiorentini and Berardi (1984). This outcome gives weight to the hypothesis that the special frequency channels underlying these tasks have the same properties in the two hemispheres.

Our results enable us to make suggestions as to the stage of information processing at which hemispheric differentiation may come into play. The absence of hemispheric differences observed in our study, however, makes it plausible that gratings are processed at a low level of sensory information processing, where a pattern is analyzed by both hemispheres. Thus, our data confirm the notion that hemispheric asymmetry does not appear in the perception of simple features of a visual pattern such as contour, luminance, sound volume, grating, and touch (Beaton \& Blakemore, 1981; Dimond \& Beaumont, 1974; Moscovitch, 1979; Moscovitch et al., 1976; Rotkin et al., 1977; Scotti \& Spinnler, 1970; Sergent, 1982, 1983; Wood, 1975). According to these authors, hemispheric asymmetry comes into play only at subsequent processing stages, at which higher order features, such as phonemes, words, or facial features, are identified. Some evidence in support of this notion has been contributed by Fiorentini and Berardi (1984), who found that comparison of simple gratings, such as those used in our study, shows no hemispheric differences, whereas a superiority of the right hemisphere appears in the processing of complex gratings. According to these authors, the perception of complex gratings is mediated by a different neuronal mechanism at a higher level of visual information processing. It is probable that hemispheric differences would appear when using other patterns of gratings, such as those used by Pollen, Nagler, Dougman, Kronauer, and Covanagh (1984), who found that cells react selectively to gratings of specific spatial frequency in posterior inferotemporal cortex in the owl monkey.
The reported results warrant some comments on the various models of hemispheric differentiation in sensory information processing (Allen's survey, 1983). The absence of hemispheric differences in grating perception suggests the inadequacy of unilateral specialization models, which postulate a distinct functional differentiation of the two hemispheres, and supports bilateral models, which postulate that both hemispheres in the normal brain have some share (either equal or not) in the processing of all sensory information. Our results suggest that the latter models fit the earliest stages of information processing in any case. At the same time, our data do not bear on the issue of hemispheric interaction as subsumed by cooperative interaction models, on the one hand, and negative interaction models (implying mutual or unilateral inhibition), on the other.

The shorter reaction times to same than to different stimuli are worth further discussion. The same tendency-fewer errors to same than to different stimuli-was observed in our analysis of errors. This finding has been fairly often reported in experiments of verbal material (e.g., Bagnara, Boles, Simion, \& Umiltà, 1982, 1983; Boles \& Eveland, 1983; Czachowska-Sieszycka, Szelag, \& Jastreboff, 1986; Howard, Kronseder, \& Sissions, 1981; Moscovitch et al., 1976; Nickerson, 1972, 1978; Polich, 1980, 1982; Proctor, 1981). Our study suggests that the tendency is of a general type; that is, it is not restricted to one type of material.

The finding that the matching of same stimuli takes less time than the matching of different stimuli with both verbal material and nonverbal material suggests that the process involved may consist of hypothesis testing and that the first hypothesis to be tested by the physiological system may be the identity hypothesis.

\section{REFERENCES}

Allen M. (1983). Models of hemispheric specialization. Psychological Bulletin, 93, 73-104.

Bagnara, S., Boles, D. B., Simion, F., \& Umiltì, C. (1982). Can an analytic/holistic dichotomy explain hemispheric asymmetries? Cortex, 18, 67-78.

Bagnara, S., Boles, D. B., Simion, F., \& Umiltà, C. (1983). Symmetry and similarity effects in the comparison of visual patterns. Perception \& Psychophysics, 34, 578-584.

BeAton, A., \& Blakemore, C. (1981). Orientation selectivity of the human visual system as a function of retinal eccentricity and visual hemifield. Perception, 10, 273-282.

Boles, D. B., Eveland, D. C. (1983). Visual and phonetic codes, and the process of generation in letter matching. Journal of Experimental Psychology: Human Perception \& Performance, 9, 657-674.

Braddick, O., Campbell, F. W., \& Atkinson, J. (1978). In R. Held, H. Leibowitz, \& H. L., Teuber (Eds.), Handbook of sensory physiology (Vol. 8, pp. 3-38). Berlin: Springer.

Briggs, G. C., \& Nebes, R. D. (1975). Patterns and hand preference in a student population. Cortex, 11, 230-238.

CAMPBELL, F. W., \& MAFFi, L. (1976). Contrast and spatial frequency. In Recent progress in perception readings from Scientific American. San Francisco: W. H. Freeman.

Czachowska-Sieszycka, B., Szelag, E., \& Jastreboff, P. (1986). Task variables and hemispheric asymmetry for word matching. Polish Psychological Bulletin, 16, 87-97.

DAvidofF, J. B. (1982). Studies with non-verbal stimuli. In J. G. Beaumont (Ed.), Divided visual field studies of cerebral organization. London: Academic Press.

De Valois, R. L., Albrecht D. G., \& Thorell, L. G. (1982). Spatial frequency selectivity of cells in macaque visual cortex. Vision Research, 22, 545-560.

Dimond, S. J., \& BeAumont, J. G. (1974). Experimental studies of hemisphere function in the human brain. In S. J. Dimond \& J. G. Beaumont (Eds.), Hemispshere function in the human brain. New York: Halstead Press.

Fiorentini, A., \& Berardi, N. (1984). Right-hemisphere superiority in discrimination of spatial phase. Perception, 13, 695-709.

Hellige, J. B., \& WeBSter, R. (1979). Right-hemisphere superiority for initial stages of letter processing. Neuropsychologia, 17, 653-660. 
Howard, S. H., Kronseder, C., \& Sissions, S. K. (1981). Hemispheric asymmetry: The effect of same-different comparison. Neuropsychologia, 19, 723-727.

HowES, D., Boller, F. (1975). Simple reaction time: Evidence for focal impairment from lesions of the right hemisphere. Brain, 98, 317-322.

Kaufman, L. (1979). Perception: The world transformed. New York: Oxford University Press.

KIRK, R. E. (1968). Experimental design procedures for the behavioral sciences. Belmont, CA: Brooks/Cole.

MAFFEI, L., \& FIORENTINI, A. (1973). The visual cortex as a spatial frequency analyzer. Vision Research, 13, 1255-1267.

MAFFEI, L., \& FioRenTiNi, A. (1977). Spatial frequency rows in the striate visual cortex. Vision Research, 17, 257-264.

Moscovirch, M. (1979). Informational processing and the cerebral hemispheres. In M. S. Gazzaniga (Ed.), The handbook of behavioral neurobiology (Vol. on Neuropsychology). New York: Plenum Press.

Moscovitch, M., Sculuion, D., \& Christie, D. (1976). Early vs. late stages of processing and their relation to functional hemisphere asymmetries in face recognition. Journal of Experimental Psychology: Human Perception \& Performance, 2, 401-416.

Movshon, J. A., Thompson, I. D., \& Tolhurst, D. J. (1978). Spatial and temporal contrast sensitivity of neurones in areas 17 and 18 of the cat's visual cortex. Journal of Physiology, 283, 101-120.

Nickerson, R. S. (1972). Binary-classification reaction time: A review of some studies of human information-processing capabilities. Psychonomic Monograph Supplements, 4(17, Whole No. 65), 275-318.

Nickerson, R. S. (1978). On the time it takes to tell things apart. In J. Requin (Ed.), Attention and performance VII. Hillsdale, NJ: Erlbaum.

PenNal, B. E. (1977). Human cerebral asymmetry in color discrimination. Neuropsychologia, 15, 563-568.

Pirot, H., Pulton, T. W., \& SuTKer, L. W. (1977). Hemispheric asymmetry in reaction time to color stimuli. Perception \& Motor Skills, 45, 1151-1155.

PoLICH, J. M. (1980). Left hemisphere superiority for visual search. Cortex, 16, 39-50.

Pouch, J. M. (1982). Hemispheric differences for visual search: Serial vs. parallel processing revisited. Neuropsychologia, 20, 297-307.

Pollen, D., Nagler, M., Daugman, J., Kronauer, R., \& Covanagh, P. (1984). Use of Gabor elementary functions to probe receptive field substructure of posterior inferotemporal neurons in the owl monkey. Vision Research, 24, 233-241.

Proctor, R. W. (1981). A unified theory for matching-task phenomena. Psychological Review, 88, 291-326.

Rotkin, L., Greenwood, P., \& Gazzaniga, M. S. (1977). Psychophysics with the "split-brain" patient: Perceptual asymmetries on verbal mediation in sensory judgments. Paper presented at the Eastern Psychological Association Meeting, New York.

SCOTTI, G., \& SPINNLER, H. (1970). Colour imperception in unilateral hemisphere-damaged patients. Journal of Neurology, Neurosurgery \& Psychiatry, 33, 22-28.

SERGENT, J. (1982). Methodological and theoretical consequences of variations in exposure duration in visual laterality studies. Perception \& Psychophysics, 31, 451-461.

SERGENT, J. (1983). Role of the input in visual hemispheric asymmetries. Psychological Bulletin, 93, 481-512.

Vassilev, A., Verskaya, A.A., Manahilov, V., Mitov, D., \& LEUSHINA, L. I. (1985). Spatial vision in the left and right visual fields. Perception, 14, A38 (8th ECVP, Periscicola, Spain).

WooD, C. C. (1975). Auditory and phonetic levels of processing in speech perception: Neuropsychological and information-processing analysis. Journal of Experimental Psychology: Human Perception \& Performance, 104, 3-20.

(Manuscript received for publication September 2, 1986.) 